\title{
Study on Effect of Mixing Process on Green Sand Properties Based on Orthogonal Experimental Method
}

\author{
SHI Dequan \\ College of Material Science and \\ Engineering \\ Harbin University of Science \& \\ Technology \\ Harbin, P. R. China \\ shidequan2008@163.com
}

\author{
GAO Guili \\ College of Material Science and \\ Engineering \\ Harbin University of Science \& \\ Technology \\ Harbin, P. R. China \\ gao-guili@163.com
}

\author{
DONG Jingwei \\ School of Measurement and \\ Communications Engineering \\ Harbin University of Science \& \\ Technology \\ Harbin, P. R. China \\ djw@hrbust.edu.cn
}

\begin{abstract}
According to the orthogonal experimental method, the influences of the feeding sequence, premixing time and final mixing time on the permeability, green compressive strength, green splitting strength and shatter index are studied when the interactions of the factors are considered. The results show that the final mixing time is the most important factor that affects these property parameters of green sand. Besides the interaction between the feeding sequence and final mixing time has bigger influence on shatter index than the feeding sequence, the influence of factor interactions on permeability, green compressive and splitting strengths is lower than that of single process parameter. Comprehensively considering these four property parameters, the optimal mixing process can be obtained, namely, the quartz sand and water are first added and premixed about 4 minutes, and then the clay and coal are added and mixed about 12 minutes.
\end{abstract}

Keywords-Mixing process; properties; orthogonal experiment; Green sand

\section{INTRODUCTION}

Green sand casting has become the main casting method because of simple process, lower cost and high productivity $[1,2]$. Statistics show that the rejected castings caused by the green sand quality account for more than half of the rejected [3]. Therefore, the optimization of green sand properties has always been one of the important forefront topics in foundry. In general, the properties of green sand mainly depend on its components. However, when green sand obtains the same components, the properties also differ because of the different mixing process $[4,5]$. So, it has an important significance for improving the properties of green sand and the quality of the castings to study and optimize the mixing process.

When the interactions between the factors are taken account, the influences of the feeding sequence, premixing time and final mixing time on the permeability, green compressive strength, green splitting strength and shatter index of green sand are studied according to the orthogonal experimental method. The optimal mixing process is got, which provides the foundation for further improving the quality of green sand.

This work was supported by the Foundation for University Key Teacher of Heilongjiang Province of China (1252G025).

\section{ORTHOGONAL EXPERIMENTAL DESIGN}

Green sand is composed of quartz sand, clay, water, coal powder and other additives. When these components are uniformly mixed, the grains will be surrounded by the clay films. Thus, the green sand has the special performance [6]. During mixing, the feeding sequence, premixing time and final mixing time have important influences on the properties of green sand, and these three factors may interact. Therefore, the feeding sequence, premixing time and final mixing time are taken as the influencing factors, and their levels given according to the actual production are shown in Table I. The levels of the feeding sequence in Table I are as follows.

TABLE I. THE FACTORS AND LEVELS OF GREEN SAND COMPONENTS

\begin{tabular}{|c|c|c|c|}
\hline \multirow{2}{*}{ levels } & \multicolumn{3}{|c|}{ factors } \\
\cline { 2 - 4 } & $\begin{array}{c}\text { A: feeding } \\
\text { sequence }\end{array}$ & $\begin{array}{c}\text { B: premixing } \\
\text { time(min) }\end{array}$ & $\begin{array}{c}\text { C: final mixing } \\
\text { time(min) }\end{array}$ \\
\hline 1 & 1 & 1 & 4 \\
\hline 2 & 2 & 4 & 12 \\
\hline 3 & 3 & 7 & 20 \\
\hline
\end{tabular}

Level 1: adding the quartz sand, clay and coal $\rightarrow$ premixing $\rightarrow$ adding water $\rightarrow$ finally mixing; Level 2 : adding the quartz sand $\rightarrow$ premixing $\rightarrow$ adding the clay and coal $\rightarrow$ finally mixing; Level 3: adding the quartz sand, clay, coal and water $\rightarrow$ premixing $\rightarrow$ finally mixing.

The premixing time is that the time of the components being added between at first and second time, and the final mixing time is the time between the components being added at second time and the green sand being mixed completely.

Based on orthogonal design [7], the $\mathrm{L}_{27}\left(3^{13}\right)$ experimental scheme, as shown in Table II, is used to study the influence of the mixing process on the permeability, green compressive strength, green splitting strength and shatter index.

The components of green sand for experiments are as follows: $100 \%$ quartz sand, $7 \%$ clay, $4 \%$ water and $5 \%$ coal powder, and the roll mixer is used to mix the green sand. After the standard samples with the size of $\Phi 50 \mathrm{~mm} \times 50 \mathrm{~mm}$ are made by the SAC Hammer sampling machine, the 
permeability is first measured by the STZ tester, and then the green compressive and splitting strength are measured respectively by the XQY-2 strength tester. The shatter index is measured by the falling ball method. During the experiments, the average of three measuring data for same parameter is taken as the valid value.

TABLE II. ORTHOGONAL EXPERIMENTAL DESIGN AND RESULT ANALYSIS

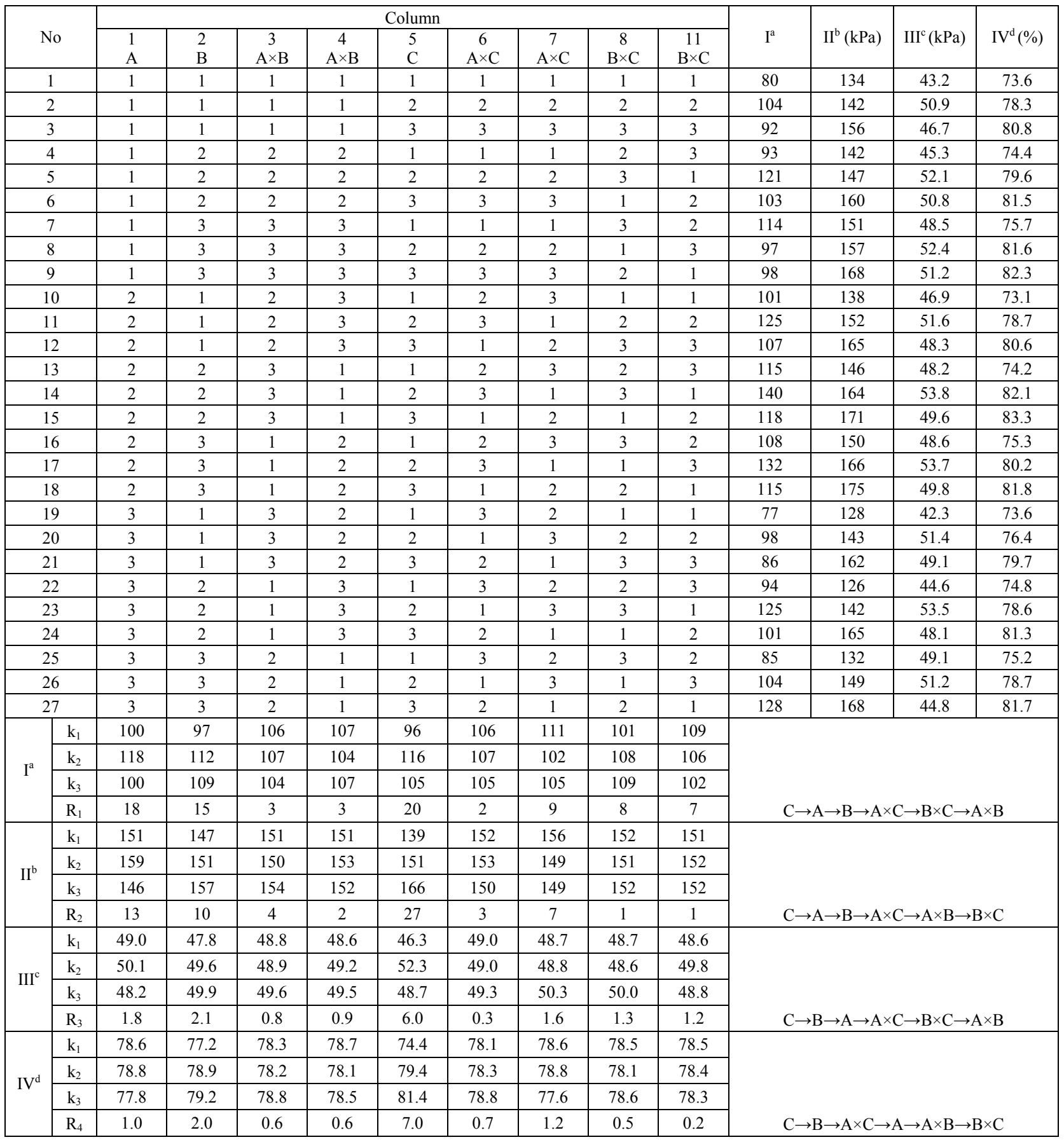

a. I is the permeability; b. II is the green compressive strength; $c$. III is the green splitting strength; $d$. IV is the shatter index

\section{RESULTS AND ANALYSIS}

The experimental results are shown in Table II. The average values $k_{i}$ and the ranges $R_{i}$ of the permeability, green compressive strength, green splitting strength and shatter index are calculated, respectively. Therefore, the sequence of the factors affecting the properties of green sand can be given by the value of the ranges $R_{i}$. It can be seen from the ranges $R_{i}$ that the interactions between the feeding sequence, premixing time and final mixing time do exist. So, 
when the optimal levels of the factors are decided, the interactions must be further analyzed. The following is the further analysis for each property parameter.

\section{A. Permeability}

The calculation results for permeability in Table II show that the interactions of the factors do exist and the influence sequence is $\mathrm{C} \rightarrow \mathrm{A} \rightarrow \mathrm{B} \rightarrow \mathrm{A} \times \mathrm{C} \rightarrow \mathrm{B} \times \mathrm{C} \rightarrow \mathrm{A} \times \mathrm{B}$, that is, the final mixing time $\rightarrow$ feeding sequence $\rightarrow$ premixing time $\rightarrow$ interaction between the feeding sequence and the final mixing time $\rightarrow$ interaction between the premixing time and final mixing time $\rightarrow$ interaction between the feeding sequence and premixing time. The interactive data of $\mathrm{A} \times \mathrm{B}, \mathrm{B} \times \mathrm{C}$ and $\mathrm{C} \times \mathrm{A}$ can be obtained from Table II, and thus the corresponding interactive curve is shown in Fig.1.
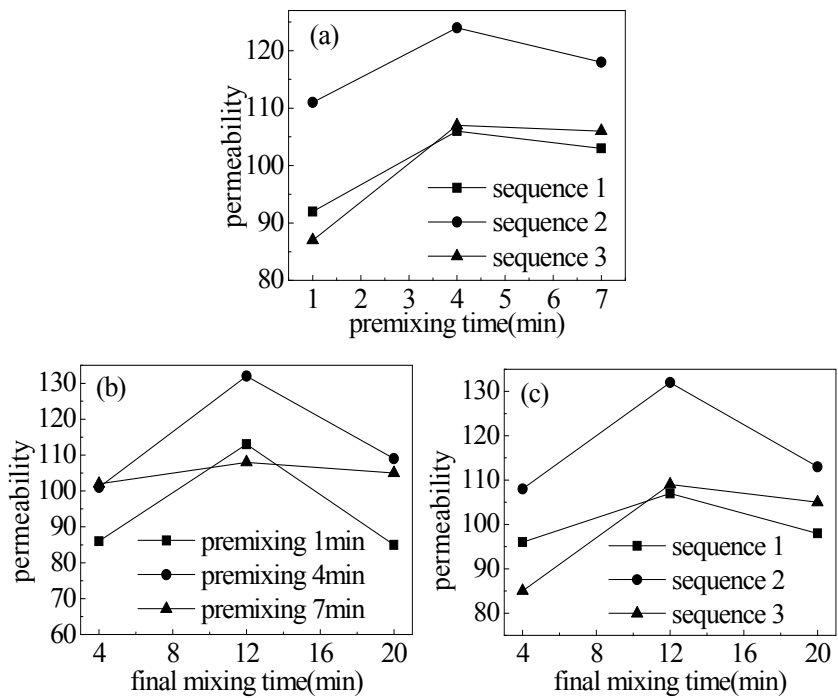

Figure 1 The interactive diagram of factors for permeability: (a) feeding sequence and premixing time; (b) premixing time final mixing time; (c) final mixing time and feeding sequence.

From Fig.1(a) and Fig.1(c) it can be seen that the feeding sequence has an important impact on the permeability of green sand. The influence of the sequence 2 is bigger than the sequence 1 and 3 . However, for the same feeding sequence, the permeability will go up and then down with the increase of mixing time. This can be explained as follows. When the clay, water and sand are sufficiently mixed, the complete clay films will form and the green sand has high permeability. But with the increase of the mixing time, the clay films will be destroyed by the mechanical function and the heat function generated from the friction. As a result, the permeability will drop down. The Fig.1(b) also indicates that the final mixing time greatly impacts on the permeability and the interaction between the premixing time and final mixing time is larger than two others. Accordingly, the optimal combination of the factors is $\mathrm{A} 2 \mathrm{~B} 2 \mathrm{C} 2$. That is to say, the optimal mixing process for the permeability is that the quartz sand and water are first premixed for 4 minutes, and then the clay and coal are added and mixed for 12 minutes.

\section{B. Green compressive strength}

It can be concluded from Table 2 that the factor sequence for compressive strength is $\mathrm{C} \rightarrow \mathrm{A} \rightarrow \mathrm{B} \rightarrow \mathrm{A} \times \mathrm{C} \rightarrow \mathrm{A} \times \mathrm{B} \rightarrow \mathrm{B} \times \mathrm{C}$, namely, the final mixing time $\rightarrow$ feeding sequence $\rightarrow$ premixing time $\rightarrow$ interaction between the feeding sequence and final mixing time $\rightarrow$ interaction between the feeding sequence and premixing time $\rightarrow$ interaction between the premixing time and final mixing time. Table 2 shows that there are small interactions between the feeding sequence and premixing time, and between the premixing time and final mixing time. So, they can be ignored. The interactive curves of $\mathrm{A} \times \mathrm{B}, \mathrm{B} \times \mathrm{C}$ and $\mathrm{A} \times \mathrm{C}$ are shown in Fig.2.
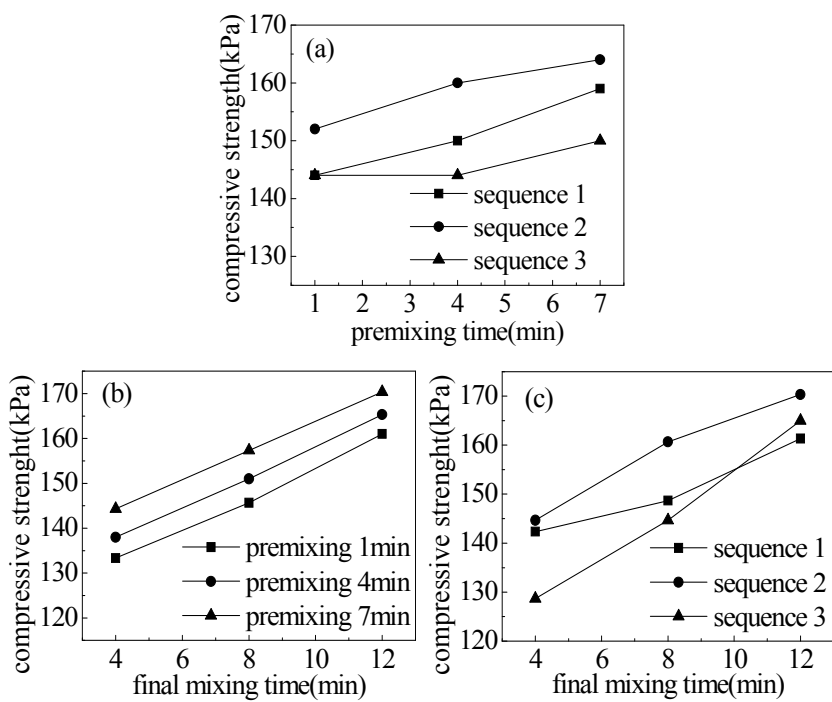

Figure 2 The interactive diagram of factors for green compressive strength: (a) premixing time and feeding sequence; (b) final mixing time and premixing time; (c) final mixing time and feeding sequence.

Fig.2 shows that the green compressive strength keeps increasing with the mixing time, which is in accordance with the result of literature [8]. In addition, it shows that there are no interactions between the feeding sequence and premixing time, and between the final mixing time and premixing time. In Fig.2(b), high green compressive strength can be also obtained when the premixing time is 7 minutes. However, By comparing with Fig.2(a) and Fig.2(c), A2B2C2 is designed as the optimal combination. Therefore, the suitable mixing process for the compressive strength is that the sand and water are first premixed 4 minutes, and the clay and coal are added and mixed 12 minutes.

\section{Green splitting strength}

We can conclude from Table 2 that the sequence of the factors affecting the green splitting strength is $\mathrm{C} \rightarrow \mathrm{B} \rightarrow \mathrm{A} \rightarrow \mathrm{A} \times \mathrm{C} \rightarrow \mathrm{B} \times \mathrm{C} \rightarrow \mathrm{A} \times \mathrm{B}$, namely, the final mixing time $\rightarrow$ premixing time $\rightarrow$ feeding sequence $\rightarrow$ interaction between the feeding sequence and final mixing time $\rightarrow$ interaction between premixing time and final mixing time. The interaction between the feeding sequence and premixing time has little influence on the green splitting strength, and its influence can be neglected. The interactive curves of $\mathrm{A} \times \mathrm{C}$, $\mathrm{B} \times \mathrm{C}$ and $\mathrm{A} \times \mathrm{B}$ are shown in Fig.3. 

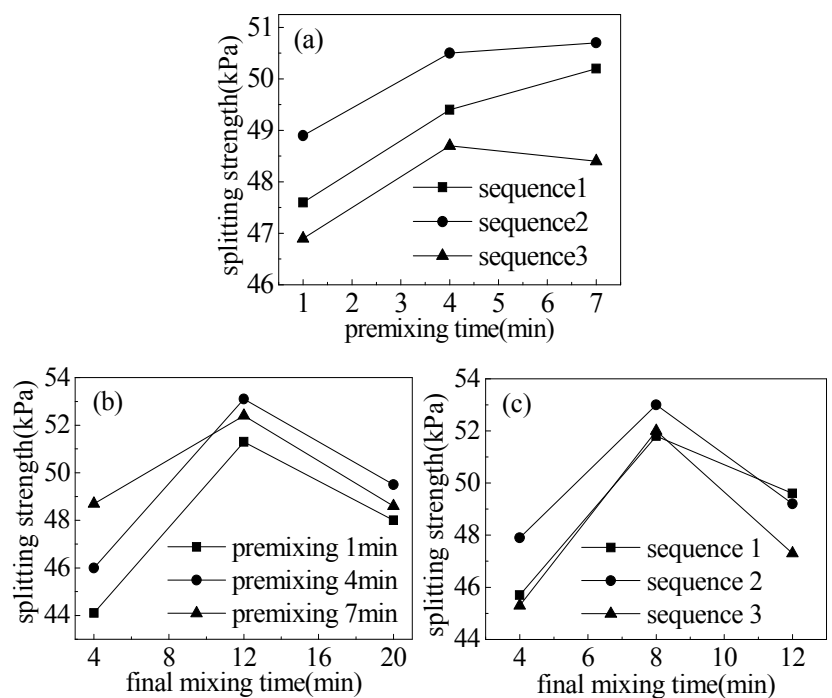

Figure 3 The interactive diagram of factors for green splitting strength: (a) premixing time and feeding sequence; (b) final mixing time and premixing time; (c) final mixing time and feeding sequence.

Fig. 3 shows that the interaction of $\mathrm{A} \times \mathrm{B}$ does not exist while the interaction of $\mathrm{A} \times \mathrm{C}$ is too big. With the increase of the mixing time, the green splitting strength goes up and then down, which differs from the change of the green compressive strength. This mainly relates to the clay films. With the formation of the complete clay films, the green splitting strength will become bigger and bigger, and in the end it reaches up to the maximum. But the mixing time is longer, parts of the films will be destroyed due to the mechanical damage and the friction heat, and thus the splitting strength will reduce. Certainly, the film damage can also degenerate the green compressive strength. However, the coal plays an important role in enhancing the compressive strength with the mixing time extension, and this effect is much larger than the clay film damage. Therefore, the green compressive strength has been increasing. The optimal mixing process for green splitting strength drawn from Fig.2 is A2B2C2.

\section{Shatter Index}

The results in Table 2 indicate that the factor sequence of affecting the shatter index is $\mathrm{C} \rightarrow \mathrm{B} \rightarrow \mathrm{A} \times \mathrm{C} \rightarrow \mathrm{A} \rightarrow \mathrm{A} \times \mathrm{B} \rightarrow \mathrm{B} \times \mathrm{C}$, namely, the final mixing time $\rightarrow$ premixing time $\rightarrow$ interaction between feeding sequence and final mixing time $\rightarrow$ feeding sequence $\rightarrow$ interaction between feeding sequence and premixing time $\rightarrow$ interaction between premixing time and final mixing time. The interactive curves of the factors for shatter index are shown in Fig.4.

It can be seen from Fig. 4 that the interaction between the feeding sequence and final mixing time is very important, and there is no interaction between the feeding sequence and premixing time. According to the industrial requirement of about $80 \%$ shatter index, the optimal mixing process is that the sand and water are premixed 4 minutes, and then the clay and coal are added and mixed 12 minutes. If the efficiency is not considered, the process that the sand, clay and coal are premixed 4 minutes, and water are added and mixed 12 minutes can meet the requirement of about $80 \%$ shatter index.
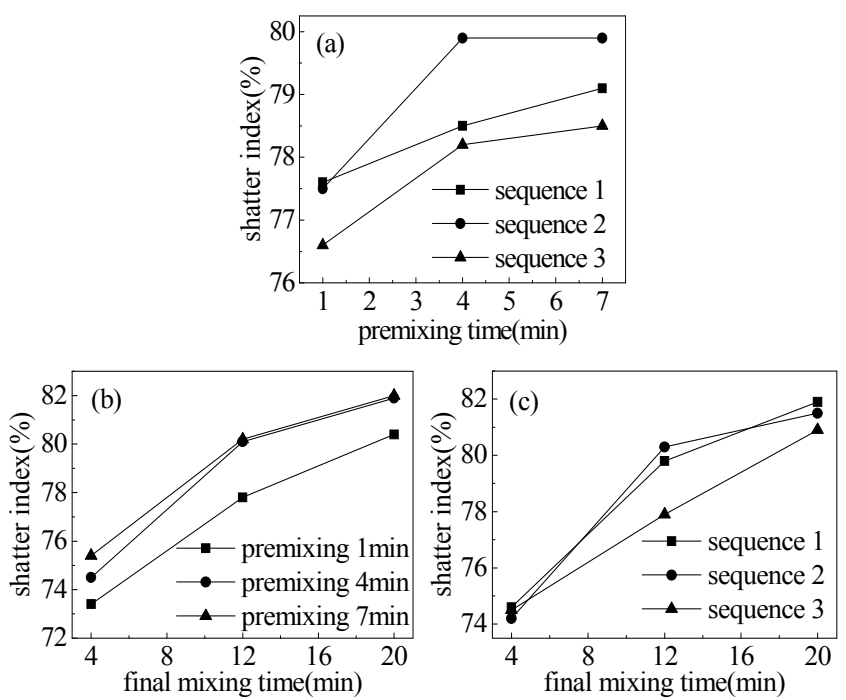

Figure 4 The interactive diagram of factors for shatter index: (a) feeding sequence and premixing time; (b) final mixing time and premixing time; (c) feeding sequence and final mixing time.

\section{CONCLUSIONS}

The final mixing time is the main and important factor that affects the permeability, green compressive strength, green splitting strength and shatter index of green sand. Except the interaction between the feeding sequence and final mixing time that remarkably affects the shatter index, the influences of the other interactions are lower than the each process parameter. The influence of the feeding sequence is smaller than that of final mixing time on the permeability and green compressive strength while bigger on the green splitting strength. Considering these four property parameters, the optimal mixing process is that the sand and water are premixed 4 minutes, and then the clay and coal are added and mixed 12 minutes.

\section{REFERENCES}

[1] Y. Chang, and H, Hocheng, "The flowability of bentonite bonded green molding sand," Journal of Materials Processing Technology, vol. 113, pp.238-244, June 2001.

[2] S. G. Baker, "Building the foundation for green sand," Modern Casting, vol. 95, pp. 26-29, August 2005.

[3] R. L. Beaman, "The sand controversy: Does core sand harm your green sand?" Modern casting, vol. 94, pp. 34-37, May 2004.

[4] S. M. Strobl, D. V. Silsby, "Controlling hot sand to ensure mold, casting quality, " Modern Casting, vol. 91, pp. 42-44, February 2001.

[5] J. M. Beaman, J. F. Cuttino, and E. P. Morse, "Parameter influence on dimensional variation in green sand iron castings," AFS Transactions, vol. 115, pp. 349-366, February 2007.

[6] M. B. Krysiak, "New conditioning practice improves sand performance," Modern Casting, vol. 90, pp. 40-42, February 2000.

[7] W. Cui, X. Li, S. Zhou, and J. Weng, "Investigation on process parameters of electrospinning system through orthogonal experimental design,” Journal of Applied Polymer Science, vol. 103, pp. 3105-3112, December 2006.

[8] Z. Li, X. L. Li, and J. Tian, "Influence of sand compacting-pulling force on sand molding on EPC," Journal of Hebei University of Science and Technology, vol. 23, pp. 52-55, March 2002. 